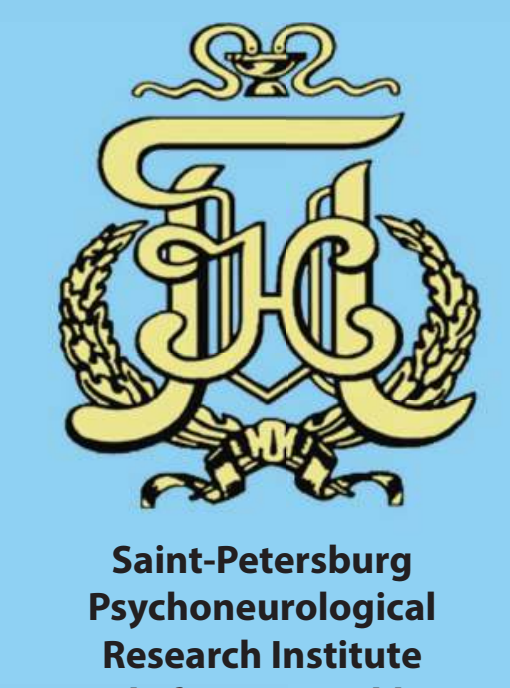

\title{
The neuroinflammation and neurodegeneration in epileptic patients with affective disorders
}

\author{
N. Sivakova', L. Lipatova', A. Kotsubinskyi²
}

X dr.sivakovan@gmail.com

'National Medical Research Centre of Psychiatry and Neurology named after V.M. Bekhterev, Department of Epilepsy, Saint-Petersburg, Russia. ${ }^{2}$ National Medical Research Centre of Psychiatry and Neurology named after V.M. Bekhterev, Department of Psychiatry, Saint-Petersburg, Russia.

\section{Background}

At present time, there are many experimental and clinical study on the inflammatory theory of epileptogenesis and depressive disorders [1,2]. The activation of microglia and astrogliosis contribute the chronic inflammatory process in epilepsy and damage neurons. The inflammation in the central nervous system based on damage to the blood-brain barrier (BBB) [3]. Cytokines influence on neuronal transmission of mediators and contribute the development of hyperexcitability of neurons [4]. The cell-mediated immune activation and the process of inflammation induce the dysregulation of a brain-derived neurotrophic factor (BDNF) and decrease in the hippocampal neurogenesis and neurodegeneration associated with epileptogenesis and the development of depression [5].

\section{Objectives}

The aim is to investigate the cytokine status and concentration of BDNF in blood plasma in epileptic patients (EP) with associated depression.

\section{Materials and Methods}

The concentration of cytokines IL-1 $\beta$, IL-2, IL-6, IL-8, IL-10, TNF- $\alpha$, RAIL-1, sIL-2R and BDNF were analyzed in blood and cerebrospinal fluid (CSF) samples of $60 \mathrm{PE}$ and 31 healthy donors (HD) using enzyme-linked immunosorbent assay (ELISA).

\section{Results}

The study showed a significant disbalance of cytokines: the increased levels of pro-inflammatory cytokines (IL-1 $\beta(306,5 \pm 14,0$ $\mathrm{pg} / \mathrm{ml})$, IL-8 $(157,1 \pm 99,4 \mathrm{pg} / \mathrm{ml})$ and TNF-a $(14 \pm 3 \mathrm{pg} / \mathrm{ml}))$, decrease of the concentration of the receptor antagonist IL-1 (RAIL-1) (38 $\mathrm{pg} / \mathrm{ml}$ ) and significantly reduced the content of BDNF $(4448,9 \pm 780,4 \mathrm{pg} / \mathrm{ml})$.

\begin{tabular}{|c|c|c|}
\hline Cytokine (pg/ml) & Epileptic patients & Healthy donors \\
\hline \multicolumn{3}{|c|}{ In blood (plasma) } \\
\hline IL-1b & $306,5 \pm 4,0$ & $0,36 \pm 0,01$ \\
\hline RAIL-1 & $38,1 \pm 23,1$ & $420 \pm 116$ \\
\hline IL-8 & $157,1 \pm 99,4$ & $0,94 \pm 0,2$ \\
\hline
\end{tabular}

In the cerebrospinal fluid

\begin{tabular}{|l|c|c|}
\hline IL-1b & $77,1 \pm 17,3$ & N/A \\
\hline RAIL-1 & 0 & N/A \\
\hline IL-8 & $6,4 \pm 2,5$ & N/A \\
\hline
\end{tabular}

Tabl. 1. The concentration of cytokines IL-1 $\beta, I L-8$, RAIL-1 in plasma and cerebrospinal fluid of patients with epilepsy.

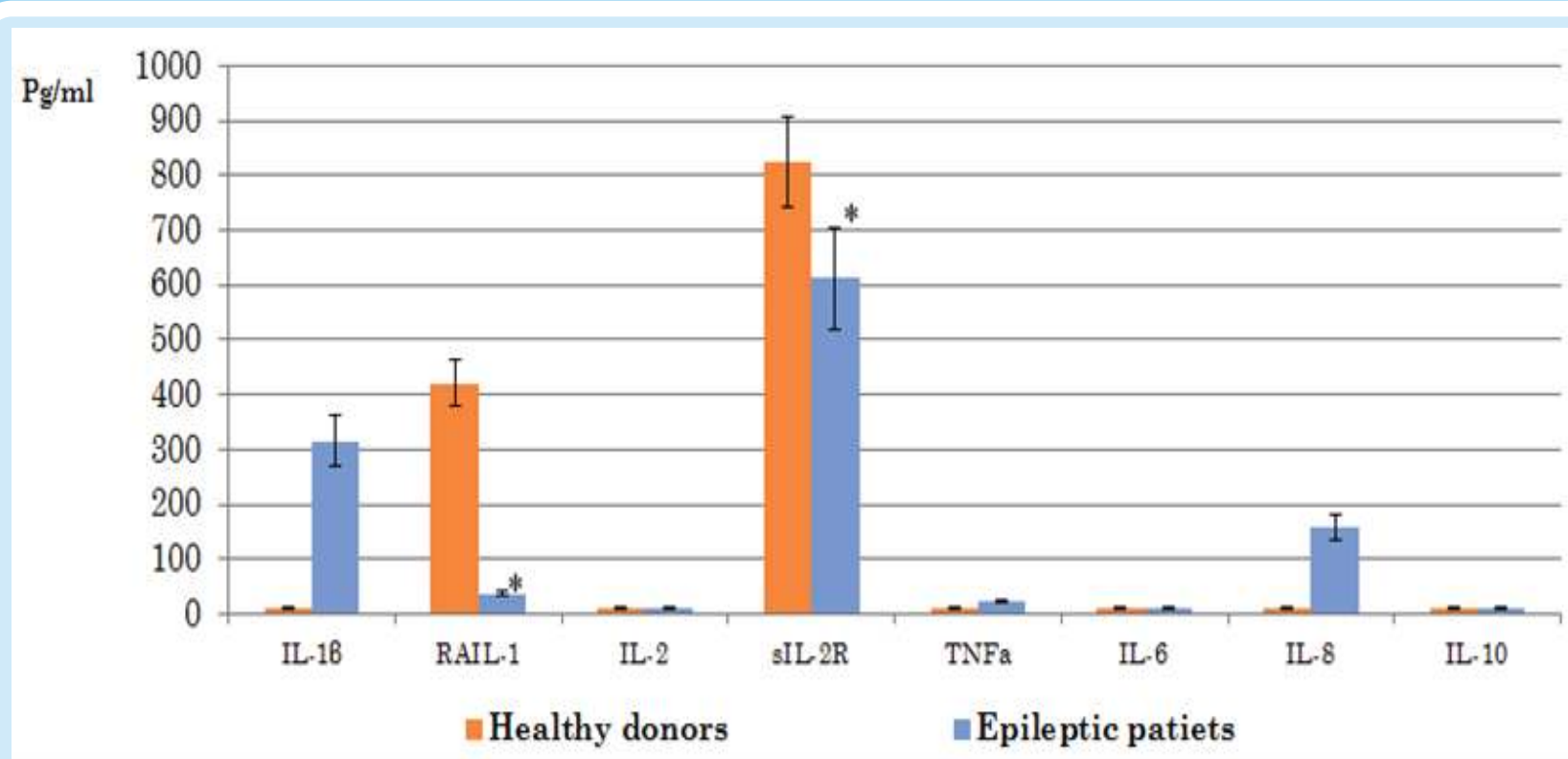

Fig. 1. The concentration of cytokines in blood plasma of patients with epilepsy and healthy donors.

The direct correlation established between immune disbalance and the presence of depressive disorders in $\operatorname{EP}(r=0,67 ; p<0,01)(r=0,71$; $p<0,01)(r=-0,83 ; p<0,01)$ (Fig. 1).

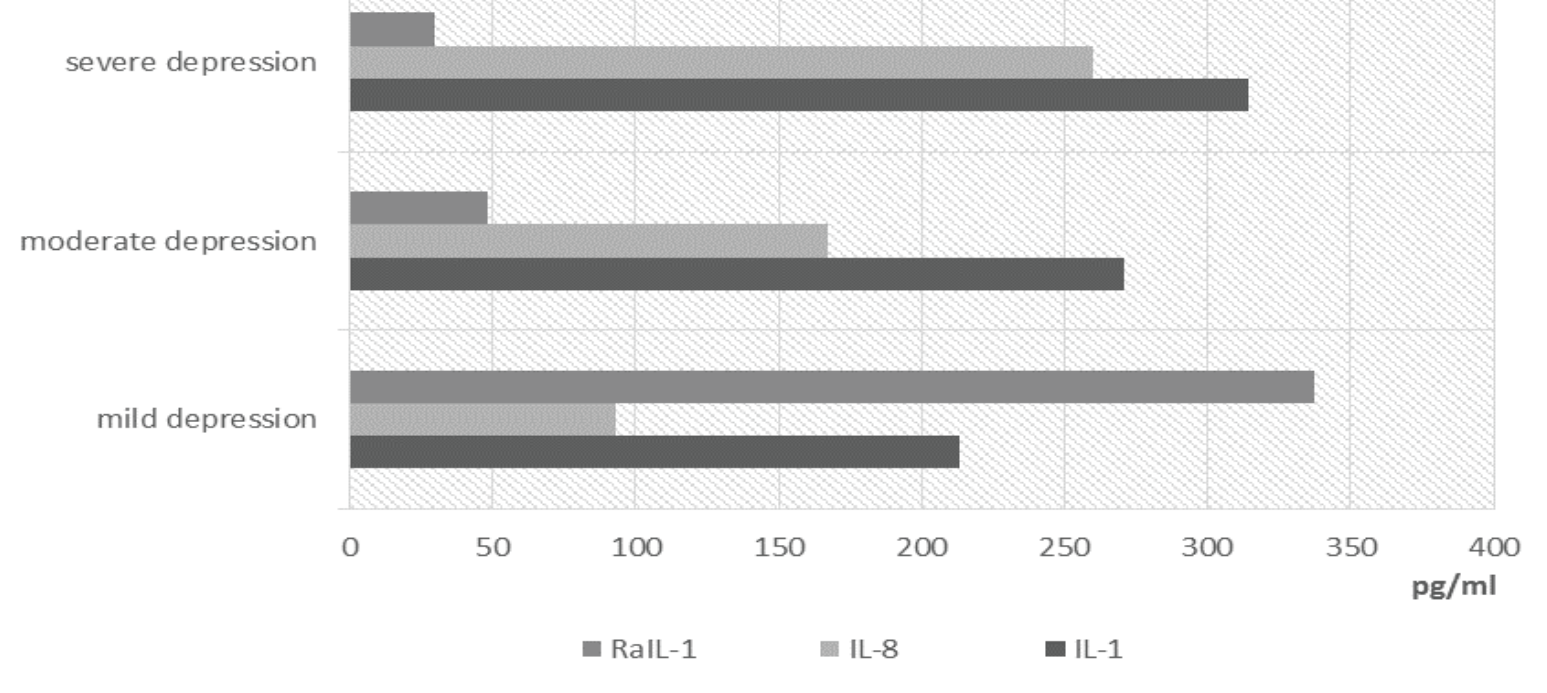

Fig. 2. The level of cytokines in PE with various depressive disorders.

\section{Conclusion}

The results confirm the data on the inflammatory and neurodegenerative hypothesis of epilepsy and depressive disorders. The immune disbalance is more expressed in EP with severe depressive disorders.

\section{References}

1) De Simoni M.G., Perego C., Ravizza T., Moneta D., Conti M., Marchesi F., Vezzani A., 2002. Inflammatory cytokines and related genes are induced in the rat hippocampus by limbic status epilepticus. European Journal of Neuroscience 12(7), 2623-2633.

2) Lehtimäki K.A., Keränen T., Huhtala H., Hurme M., Ollikainen J., Honkaniemi J., Peltola J., 2004. Regulation of IL-6 system in cerebrospinal fluid and serum compartments by seizures: the effect of seizure type and duration. Neuroimmunology 152(1), 121-125.

3) Vezzani A., Granata T., 2005. Brain inflammation in epilepsy: experimental and clinical evidence. Epilepsia 46(11), 1724-1743.

4) Vezzani A., Balosso S., Ravizza T., 2008. The role of cytokines in the pathophysiology of epilepsy. Brain, Behavior, and Immunity 22(6), 797-803.

5) LaFrance W. C. Jr. W.C., Leaver K., Stopa E. G., Papandonatos G. D., Blum A. S., 2010. Decreased serum BDNF levels in patients with epileptic and psychogenic nonepileptic seizures. Neurology 75(14), 1285-1291. 